\title{
Influência do período de armazenamento na qualidade do ovo integral pasteurizado refrigerado
}

\author{
[Influence of storage period on refrigerated pasteurized whole egg quality]
}

I.O.P. Rêgo, S.V. Cançado*, T.C. Figueiredo, L.D.M. Menezes, D.D. Oliveira, A.L. Lima, L.G.M. Caldeira, L.R. Esser

Escola de Veterinária - Universidade Federal de Minas Gerais - Belo Horizonte, MG

\section{RESUMO}

Avaliaram-se o pH e a qualidade microbiológica de ovos integrais pasteurizados refrigerados obtidos de dois tipos de matéria-prima: o ovo in natura (comercial ) e o ovo galado (ovo fértil). Os tratamentos foram dispostos no delineamento inteiramente ao acaso, em parcelas subdivididas, sendo na parcela dois tipos de ovos integrais pasteurizados, o comercial e o galado, e na subparcela quatro períodos de estocagem sob temperatura de refrigeração, um, sete, 14 e 21 dias. Não foi observada a presença de Salmonella spp. em nenhuma amostra analisada, e para os ovos comerciais, o período de estocagem não contribuiu para o aumento $(\mathrm{P}>0,05)$ da contaminação por mesófilos aeróbios, coliformes a $35^{\circ} \mathrm{C}$, Staphylococcus spp. e bolores e leveduras. Para as amostras de ovos galados, o período de armazenamento influenciou no aumento $(\mathrm{P}<0,05)$ da contagem de mesófilos aeróbios, coliformes a $35^{\circ} \mathrm{C}$, bolores e leveduras, e Staphylococcus spp. Os valores de $\mathrm{pH}$ aumentaram durante os primeiros dias do armazenamento e depois voltaram a diminuir. Concluiu-se que os ovos integrais galados pasteurizados apresentam pior qualidade em relação aos ovos integrais comerciais pasteurizados, e que o período de validade sob refrigeração desses tipos de ovos poderia ser de sete e 14 dias, respectivamente.

Palavras-chave: ovo integral pasteurizado refrigerado, ovo galado, armazenamento, microbiologia, $\mathrm{pH}$

\begin{abstract}
The $\mathrm{pH}$ and microbiological quality of refrigerated pasteurized whole eggs at $4^{\circ} \mathrm{C}$ obtained from two types of raw materials, in nature (commercial) egg and the fertile egg were evaluated. The treatments were arranged in a completely randomized split plot design, the two types of pasteurized whole eggs (commercial and fertile) were alloted to the plots and four periods of storage under refrigeration (one, seven, 14 and 21 days) to the split plot. The presence of Salmonella spp. was not observed in the samples and the commercial pasteurized whole egg storage period did not contribute to the increase $(P>0.05)$ in mesophilic aerobic coliforms at $35^{\circ} \mathrm{C}$, Staphylococcus spp and mold and yeast contamination. For samples of fertile pasteurized whole eggs, the storage period influenced the increased $(P<0.05)$ count of mesophilic aerobic, coliforms at $35^{\circ} \mathrm{C}$, mold and yeast and Staphylococcus spp. The pH values rose during the first days of storage and then decreased again. It was concluded that fertile pasteurized whole eggs have lower quality than the commercial pasteurized whole eggs, and that the shelf life of these could be seven and 14 days, respectively.
\end{abstract}

Keywords: refrigerated pasteurized whole egg, fertile egg, storage, microbiology, $\mathrm{pH}$

Recebido em 23 de maio de 2010

Aceito em 13 de março de 2012

*Autor para correspondência (corresponding author)

E-mail: silvana@vet.ufmg.br 


\section{INTRODUÇÃO}

$\mathrm{Na}$ indústria de alimentos, o ovo pasteurizado ou desidratado é utilizado preferencialmente ao ovo in natura (ovo em casca), pois, além de conservar o sabor, a cor, o valor nutritivo e as propriedades funcionais, apresenta vantagens operacionais, como melhor uniformidade, menor espaço para armazenamento e facilidade para medir as porções (Aragon-Alegro et al., 2005).

Segundo o Ministério da Agricultura, Pecuária e Abastecimento (MAPA), ovo integral é o ovo em natureza desprovido de casca e que conserva as proporções naturais de gema e de clara (Brasil, 1990). O ovo destinado à industrialização deve apresentar conteúdo com qualidade para uso comestível, sendo que a casca deve estar íntegra e livre de sujeira aderente e material estranho. $\mathrm{O}$ ovo trincado ou que apresenta fenda ou quebra na casca pode ser utilizado no processamento normal, desde que as membranas da casca não estejam rompidas. Caso haja o rompimento da membrana da casca, poderão ser utilizados somente os ovos que apresentarem gema intacta e não aderente à casca (Brasil, 1991; Brasil, 1997). Os ovos galados, ovos produzidos por matrizes pesadas que foram rejeitados para incubação, também podem ser pasteurizados, desde que não haja mancha orbitária ou desenvolvimento avançado do embrião (Brasil, 1997).

A faixa de $\mathrm{pH}$ do ovo integral líquido pasteurizado pode variar entre 7,0 e 7,6, dependendo do histórico - fresco, temperatura de estocagem etc. Assim como no $\mathrm{pH}$ do albúmen medido no ovo in natura, o $\mathrm{pH}$ da mistura albúmen e gema do ovo integral líquido depende da quantidade de dióxido de carbono no interior do ovo no período da quebra (Stadelman e Cotterill, 1995).

O ovo é um dos alimentos mais completos para a alimentação humana, apresentando uma composição rica em vitaminas, minerais, ácidos graxos e proteínas que reúnem vários aminoácidos essenciais de excelente valor biológico. Por ser rico em nutrientes e de alta digestibilidade, exige alguns cuidados para que não se transforme em meio para crescimento microbiano e para que chegue ao consumidor com qualidade. Como o ovo que é utilizado para pasteurização é proveniente de matéria-prima mais passível de contaminação, ovo trincado e ovo galado, ele se torna um alimento mais vulnerável à deterioração por micro-organismos. Esta contaminação inicial do ovo antes da pasteurização pode causar modificações físicoquímicas e organolépticas que limitam sua durabilidade (Franco e Landgraf, 1996; Dias et al., 2002; American..., 2004; Jay et al., 2005; Koblitz, 2008; Hara-Kudo e Takatori, 2009).

O ovo pasteurizado pode ser contaminado de várias maneiras, incluindo a alta contaminação microbiana da matéria-prima, a falha do binômio tempo-temperatura na pasteurização ou a contaminação pós-processamento. Por isso, a pasteurização adequada e a correta higienização do equipamento são determinantes da microbiota residual final, e é essa microbiota que vai determinar a vida de prateleira do produto, juntamente com as condições de refrigeração. A combinação entre o aquecimento e a embalagem asséptica também contribui para aumentar o período de vida de prateleira do ovo integral pasteurizado (Hamid-Samimi e Swartzel, 1985; Ball et al., 1987; Hara-Kudo e Takatori, 2009).

Com base nesses aspectos e por haver pouca disponibilidade de pesquisas científicas a respeito da qualidade do ovo integral pasteurizado refrigerado produzido no Brasil, este trabalho teve como objetivo verificar a influência do período de armazenamento nos valores de $\mathrm{pH}$ e nas características microbiológicas do ovo integral pasteurizado refrigerado obtido de dois tipos de matériasprimas: o ovo integral comercial e o ovo integral galado.

\section{MATERIAL E MÉTODOS}

Foram analisadas 12 amostras de diferentes lotes de ovos integrais pasteurizados refrigerados. Como matéria-prima da pasteurização, foram utilizados os ovos comerciais - ovos in natura desclassificados por peso, trincados, quebrados e os ovos galados - ovos férteis desclassificados para a incubação em razão do baixo peso e/ou do excedente de produção. Após a pasteurização de seis lotes de produção de ovos comerciais, foi coletada uma amostra de um litro de cada lote. Também foram coletadas seis amostras de um litro de seis lotes de produção de ovos galados pasteurizados. Desta maneira, cada amostra coletada de ovo pasteurizado representava um 
lote de produção (uma repetição). Todos os ovos foram quebrados em máquina de quebra automática de ovos e passaram por pasteurização rápida, tipo Hight Temperature Short Time (HTST), sendo que o binômio tempo/temperatura utilizado foi de $60^{\circ} \mathrm{C}$ por 3,5 minutos. Não foi adicionado $\mathrm{o}$ peróxido de hidrogênio (coadjuvante de tecnologia de fabricação).

Todas as 12 amostras de ovos pasteurizados coletadas, seis de ovos integrais comerciais e seis de ovos integrais galados, foram divididas em quatro partes iguais e colocadas em quatro recipientes estéreis de $250 \mathrm{~mL}$ cada. Os quatro recipientes de cada lote de amostra foram datados e armazenados sob refrigeração $\left(4^{\circ} \mathrm{C}\right)$ por períodos de até 21 dias (dessa maneira, a amostra que foi avaliada com um dia de refrigeração foi a mesma que foi avaliada posteriormente). Durante todo o experimento, as temperaturas máxima e mínima do local de estocagem foram registradas de 24 em 24 horas, em termômetro digital, a temperatura de refrigeração média do local de estocagem foi de $3,5^{\circ} \mathrm{C}$ e as temperaturas máxima e mínima foram $4,8^{\circ} \mathrm{C}$ e $2,2^{\circ} \mathrm{C}$, respectivamente.

Realizaram-se a medição de $\mathrm{pH}$, segundo Brasil (1999), e as seguintes análises microbiológicas: número mais provável $(\mathrm{NMP} / \mathrm{mL})$ de coliformes totais e termotolerantes e a contagem de Staphylococcus spp. de acordo com a Instrução Normativa 62 (Brasil, 2003). A pesquisa de Salmonella spp. foi realizada pelo sistema Vitek Immunodiagnostic Assay System (Vidas, BioMerieux, Hazelwood, MO, USA), e a contagem global de micro-organismos mesófilos aeróbios (UFC/mL) e bolores e leveduras (UFC/mL) pelo petrifilm ${ }^{\mathrm{TM}}$ da marca $3 \mathrm{M}^{\mathrm{TM}}$ (St. Paul, MN, USA), de acordo com AOAC (Association..., 2001).

Os tratamentos foram dispostos em parcelas subdivididas $2 \times 4$, sendo dois tipos de matériaprima empregados na produção de ovos pasteurizados (ovo comercial e ovo galado) na parcela, e quatro períodos de estocagem na subparcela (1, 7, 14 e 21 dias), totalizando oito tratamentos com seis repetições cada. Os fatores tempo de estocagem, matéria-prima utilizada e $\mathrm{pH}$ foram submetidos à análise de regressão. Para as variáveis microbiológicas, os resultados foram submetidos à análise estatística não paramétrica, sendo que na parcela foi realizado o teste de Kruskal-Wallis, e na subparcela o teste de Friedman. Os dados foram analisados pelo sistema informático SAS (Statistical..., 1999; Sampaio, 2002).

\section{RESULTADOS E DISCUSSÃO}

As equações de regressão e suas representações gráficas dos valores de $\mathrm{pH}$ dos ovos comerciais e galados pasteurizados em função dos dias de armazenamento sob refrigeração são apresentadas na Fig. 1. Os tipos de matériasprimas utilizados para a pasteurização e o período de armazenamento influenciaram nos valores de $\mathrm{pH}$. Foi observado alto valor de coeficiente de determinação $\left(\mathrm{R}^{2}\right)$ para as duas equações, indicando que a linha de regressão do $\mathrm{pH}$ em função do período de armazenamento se aproxima dos pontos dos dados reais observados.

Para os ovos pasteurizados, os valores de $\mathrm{pH}$ subiram e depois começaram a cair. A redução do valor de $\mathrm{pH}$ dos ovos comerciais pasteurizados foi menor e começou a ocorrer a partir do $14^{\circ}$ dia de armazenamento; já para os ovos galados pasteurizados, a queda no valor de $\mathrm{pH}$ começou a ocorrer a partir do oitavo dia de armazenamento, chegando aos 21 dias com valor menor que o valor inicial.

pode ter sido causada pela produção de ácidos graxos livres originários de lipases próprias do ovo (enzimas termoestáveis) e lipases produzidas por micro-organismos lipolíticos. Segundo Koblitz (2008), as lipases microbianas estão envolvidas no processo de aquisição de energia de micro-organismos, e estes podem estar presentes nos ovos.

Em nenhuma das 48 amostras de ovos pasteurizados analisadas foi detectada a presença de Salmonella spp. em $25 \mathrm{~mL}$, atendendo, portanto, à legislação para o ovo integral (Brasil, 1991), resultado semelhante ao encontrado por Aragon-Alegro et al. (2005). Entretanto, HaraKudo e Takatori (2009) verificaram 1,7\% $(n=298)$ de amostras de ovo líquido pasteurizado positivo para Salmonella spp. no período de 1992 a 2002, no Japão. No ovo não pasteurizado, o percentual chegou a $8,3 \%(n=907)$. 


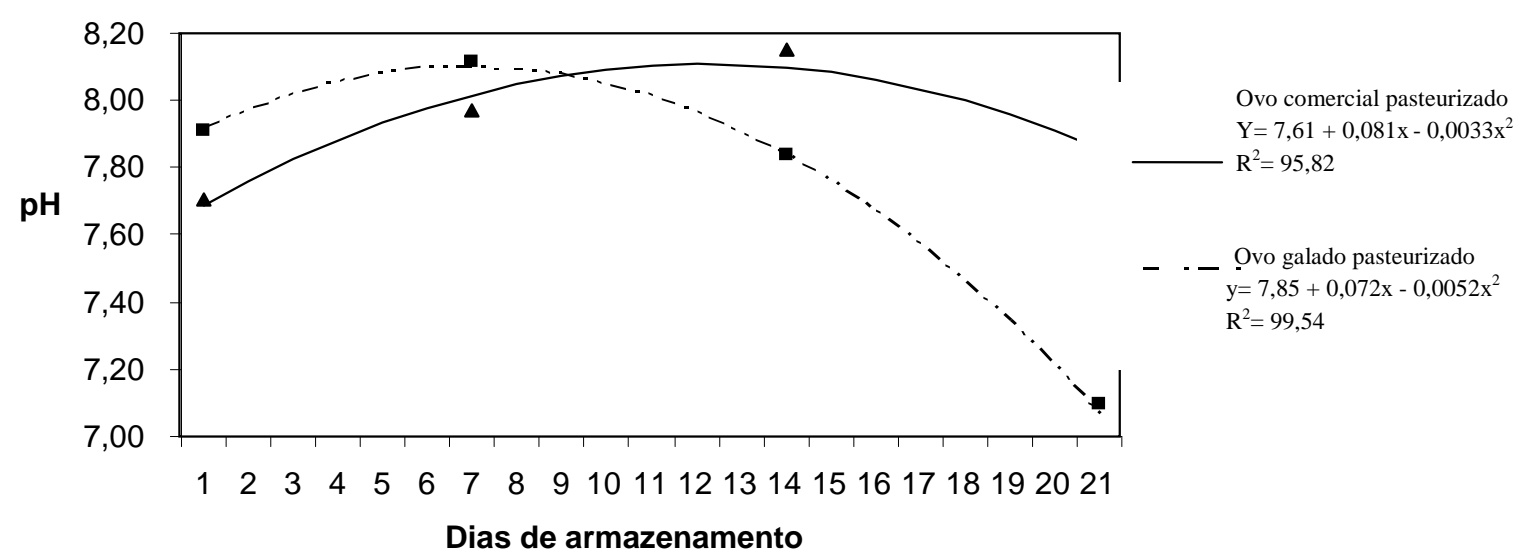

Figura 1. Gráfico de regressão dos valores de $\mathrm{pH}$ dos ovos integrais comerciais e galados pasteurizados em função dos dias de armazenamento.

A diminuição do valor de $\mathrm{pH}$ observada no armazenamento no $21^{\circ}$ dia para o ovo galado pasteurizado

Para as amostras de ovos comerciais pasteurizados, os resultados das contagens de micro-organismos mesófilos aeróbios (Tab. 1) variaram bastante em cada repetição analisada, sendo que no $21^{\circ}$ dia de avaliação, foram encontradas três amostras $(12,5 \%)$ que apresentaram valores acima do estabelecido pelo padrão para ovo integral, que é $5 \times 10^{4} \mathrm{UFC} / \mathrm{mL}$ segundo Brasil (1991). Porém, este aumento na contagem de micro-organismos mesófilos aeróbios com o aumento do período de armazenamento não foi significativo ( $\mathrm{P}>0,05)$.

Para as amostras de ovos integrais galados pasteurizados (Tab. 1), os resultados das contagens de micro-organismos mesófilos aeróbios foram mais altos. No $21^{\circ}$ dia, estas amostras apresentavam-se acima de $2,5 \times 10^{6} \mathrm{UFC} / \mathrm{mL}$ e, a partir do sétimo dia, todas as amostras já estavam acima do padrão para o ovo integral. Para estes ovos, a média da contagem de micro-organismos mesófilos da primeira semana foi menor $(\mathrm{P}<0,05)$ do que das semanas sete, 14 e 21 .

Tabela 1. Médias da contagem de micro-organismos mesófilos aeróbios em ovos integrais comerciais e galados pasteurizados armazenados sob temperatura de refrigeração por até 21 dias

\begin{tabular}{lcccc}
\hline \multirow{2}{*}{ Tipo de ovo } & \multicolumn{4}{c}{ Contagem de UFC/mL por dia de armazenamento } \\
\cline { 2 - 5 } & 1 & 7 & 14 & 21 \\
\hline Comercial & $2,5 \times 10^{3 \mathrm{Aa}}$ & $2,3 \times 10^{3 \mathrm{Aa}}$ & $2,6 \times 10^{3 \mathrm{Aa}}$ & $4,5 \times 10^{5 \mathrm{Aa}}$ \\
Galado & $3,3 \times 10^{2 \mathrm{Ba}}$ & $8,7 \times 10^{5 \mathrm{Aa}}$ & $2,2 \times 10^{6 \mathrm{Aa}}$ & $>2,5 \times 10^{6 \mathrm{Aa}}$
\end{tabular}

Médias seguidas de letras distintas, maiúsculas na linha e minúsculas na coluna, diferem entre si pelo teste de Kruskal - Wallis $(\mathrm{P}<0,05)$ para a comparação das médias dos ovos, e pelo teste de Friedman para a comparação das médias em cada tipo de ovos $(\mathrm{P}<0,05)$.

O ovo galado permanece mais tempo em contato com o ninho e com as aves e, com isso, fica mais exposto à contaminação, podendo carrear um grande número de micro-organismos para o seu interior. Porém, a temperatura de pasteurização deveria ser suficiente para inativar microorganismos, por isso a principal hipótese levantada em relação às amostras de ovo galado adquiridas para a presente pesquisa é a de que a matéria-prima antes da pasteurização estava excessivamente contaminada, já que os outros fatores, como controle do binômio tempotemperatura, embalagem e transporte, foram controlados.

A maior contagem de micro-organismos mesófilos aeróbios no ovo integral galado pasteurizado determinou neste experimento que sua vida de prateleira fosse menor, no máximo sete dias. Nestes ovos, a partir do $14^{\circ}$ dia, também foram observadas algumas alterações organolépticas, como alterações de coloração 
(mais claro) e odor pútrido. Não foram observadas diferenças significativas $(\mathrm{P}>0,05)$ quando a média de resultados destes ovos foi comparada com as médias dos resultados dos ovos integrais comerciais pasteurizados pelo teste de Kruskal - Wallis. O American Egg Board (American..., 2004) indica como valor de referência para o ovo pasteurizado contagens menores que $10^{3 \mathrm{UFC}} / \mathrm{mL}$. Na presente pesquisa, os resultados de contagem de mesófilos aeróbios em desacordo com o padrão do American Egg Board foram de 83,3\%. Estes resultados são mais elevados que os verificados por Dias et al. (2002), que encontraram para o ovo integral pasteurizado resultados da enumeração de microorganismos mesófilos aeróbios variando entre $1 \mathrm{UFC} / \mathrm{mL}$ e $1,2 \times 10^{4} \mathrm{UFC} / \mathrm{mL}$, sendo que $81,9 \%$ das amostras apresentaram valores menores que $10^{3} \mathrm{UFC} / \mathrm{mL}$. Aragon-Alegro et al. (2005) detectaram mais baixas contagens de microorganismos mesófilos aeróbios em relação à presente pesquisa.
$\mathrm{Na}$ Tab. 2, são apresentados os resultados em número mais provável (NMP) dos coliformes totais presentes nos ovos integrais comerciais e galados pasteurizados. Durante todo o período de avaliação dos ovos integrais comerciais pasteurizados, apenas uma amostra $(4,1 \%)$ no dia sete apresentou-se contaminada para coliforme total. Nos ovos integrais galados pasteurizados, duas amostras $(8,3 \%)$ apresentaram-se positivas para coliformes totais no primeiro dia, porém, no $21^{\circ}$ dia, todas as amostras foram positivas para coliformes totais. A contaminação maior apresentada no dia 21 pode ser devido ao valor de $\mathrm{pH}$ apresentado neste dia, que foi o mais baixo de todo o experimento. $\mathrm{O} \mathrm{pH}$ mais alto nos dias sete e 14 pode ter inibido o crescimento dos coliformes totais. Segundo a Instrução Normativa $n^{\circ} 1$ (Brasil, 1991), não há padrão para coliformes totais no ovo integral. A mesma Instrução determina ausência em $1 \mathrm{~mL}$ de ovo integral para os coliformes termotolerantes.

Tabela 2. Médias da contagem de coliformes totais $\left(35^{\circ} \mathrm{C}\right)$ em ovos comerciais e galados pasteurizados e armazenados sob temperatura de refrigeração até 21 dias

\begin{tabular}{lcccc}
\hline \multirow{2}{*}{ Tipo de ovo } & \multicolumn{4}{c}{ Contagem em NMP/mL por dia de armazenamento } \\
\cline { 2 - 5 } Comercial & 1 & 7 & 14 & 21 \\
Galado & $0,00 \mathrm{Aa}$ & $0,06 \mathrm{Aa}$ & $0,00 \mathrm{Aa}$ & $0,00 \mathrm{Ab}$ \\
\hline
\end{tabular}

Médias seguidas de letras distintas, maiúsculas na linha e minúsculas na coluna, diferem entre si pelo teste de Kruskal - Wallis $(\mathrm{P}<0,05)$ para a comparação das médias dos ovos, e pelo teste de Friedman para a comparação das médias em cada tipo de ovos $(\mathrm{P}<0,05)$.

A presença dos coliformes totais nos alimentos pode indicar contaminação de origem fecal ou ocorrência de enteropatógenos (Franco e Landgraf, 1996). No presente experimento, os coliformes totais variaram de <0,3 NMP a 110 NMP. Resultados mais baixos foram verificados por Dias et al. (2002), que, ao avaliarem a microbiota do ovo integral pasteurizado, encontraram valores para coliformes totais que variaram de <0,3 NMP a 4,3 NMP, sendo que $53 \%$ das amostras apresentaram número mais provável $<0,3$; os resultados menores encontrados se devem provavelmente ao tipo de matéria- prima utilizada, que era composta apenas por ovos comerciais (in natura).

Não foi observado crescimento de coliformes a $45^{\circ} \mathrm{C}$ nos ovos integrais comerciais pasteurizados ao longo do período de armazenamento. No ovo integral galado pasteurizado, foi detectada a presença de coliformes a $45^{\circ} \mathrm{C}$, apenas no primeiro dia, em uma amostra. Dias et al. (2002), ao trabalharem com ovo integral pasteurizado, encontraram em $100 \%$ das amostras avaliadas coliforme a $45^{\circ} \mathrm{C}<0,3$ NMP. A implantação de boas práticas de fabricação para os ovos in natura na granja e para os ovos pasteurizados nas indústrias de ovoprodutos reduziria a incidência de micro-organismos deteriorantes e patogênicos nos ovos, promovendo a inocuidade deste alimento para o consumidor.

O crescimento de colônias semelhantes ao Staphylococcus spp. em ágar Baird Parker foi observado em 97,9\% das placas (Tab. 3). Não foram observadas diferenças estatísticas entre os ovos integrais comerciais e galados pasteurizados. 
Tabela 3. Médias da contagem de Staphylococcus spp. em ovos integrais comerciais e galados pasteurizados armazenados sob temperatura de refrigeração até 21 dias

\begin{tabular}{lcccc}
\hline \multirow{2}{*}{ Tipo de ovo } & \multicolumn{4}{c}{ Contagem em UFC/ mL por dia de armazenamento } \\
\cline { 2 - 5 } & 1 & 7 & 14 & 21 \\
\hline Comercial & $1,33 \times 10^{2 \mathrm{Aa}}$ & $4,70 \times 10^{1 \mathrm{Aa}}$ & $1,17 \times 10^{2 \mathrm{Aa}}$ & $4,80 \times 10^{1 \mathrm{Aa}}$ \\
Galado & $2,00 \times 10^{1 \mathrm{Ba}}$ & $>2,00 \times 10^{2 \mathrm{Aa}}$ & $>2,00 \times 10^{2 \mathrm{Aa}}$ & $8,70 \times 10^{1 \mathrm{ABa}}$ \\
\hline
\end{tabular}

Médias seguidas de letras distintas, maiúsculas na linha e minúsculas na coluna, diferem entre si pelo teste de Kruskal - Wallis $(\mathrm{P}<0,05)$ para a comparação das médias dos ovos, e pelo teste de Friedman para a comparação das médias em cada tipo de ovos $(\mathrm{P}<0,05)$.

A contagem de Staphylococcus spp. na maioria das amostras estudadas foi reduzida ao fim do experimento. Essas bactérias possuem a característica morfológica de formar cachos, o que pode ter contribuído para as diferenças dos resultados encontrados, ou seja, mesmo após a homogeneização realizada antes de dividir as amostras em frascos, pode ter sido retirada uma porção da amostra mais contaminada. Essa mesma variação também foi observada por Franco e Landraf (1996) e por Jay et al. (2005). Estes últimos autores descreveram que os Staphylococcus spp. não competem bem com os outros micro-organismos.
Os resultados obtidos para a contagem de Staphylococcus coagulase positiva encontram-se na Tab. 4. A legislação prevê que, para os ovos integrais líquidos, o parâmetro é a ausência de $S$. aureus em $1 \mathrm{~mL}$. Nas amostras de ovos comerciais, foi encontrada uma amostra positiva $(4,2 \%)$ para $S$. coagulase positiva no sétimo dia de análise. Nas amostras de ovos integrais galados pasteurizados, foram encontradas quatro amostras positivas $(16,6 \%)$, sendo uma positiva no dia um e três positivas com 21 dias. Os níveis de contaminação das amostras de ovos pasteurizados foram mais altos que os descritos na literatura. Aragon-Alegro et al. (2005) detectaram baixa contagem de Staphylococcus aureus em ovo integral pasteurizado.

Tabela 4. Contagem de Staphylococcus coagulase positiva em ovos integrais comerciais e galados pasteurizados e armazenados sob temperatura de refrigeração até 21 dias

\begin{tabular}{lcccc}
\hline \multirow{2}{*}{ Tipo de ovo } & \multicolumn{4}{c}{ Contagem em UFC/mL por dia de armazenamento } \\
\cline { 2 - 5 } & 1 & 7 & 14 & 21 \\
\hline Comercial & $0,00^{\mathrm{Aa}}$ & $2,8 \times 10^{0 \mathrm{Aa}}$ & $0,00^{\mathrm{Aa}}$ & $0,00^{\mathrm{Aa}}$ \\
Galado & $0,36 \times 10^{0 \mathrm{Aa}}$ & $0,00^{\mathrm{Aa}}$ & $0,00^{\mathrm{Aa}}$ & $3,6 \times 10^{1 \mathrm{Aa}}$ \\
\hline
\end{tabular}

Médias seguidas de letras distintas, maiúsculas na linha e minúsculas na coluna, diferem entre si pelo teste de

Kruskal - Wallis $(\mathrm{P}<0,05)$ para a comparação das médias dos ovos, e pelo teste de Friedman para a comparação das médias em cada tipo de ovos $(\mathrm{P}<0,05)$.

$\mathrm{Na}$ Tab. 5, apresentam-se os resultados obtidos das análises de bolores e leveduras das amostras de ovos integrais comerciais e ovos galados pasteurizados e armazenados sob temperatura de refrigeração por um período de até 21 dias. Os resultados obtidos para os ovos integrais comerciais pasteurizados demonstram que, apesar do aumento no último dia de estocagem, este não foi significativo $(\mathrm{P}>0,05)$. Entretanto, para os ovos galados, a contaminação por bolores e leveduras aumentou $(\mathrm{P}<0,05)$ de menor que $10 \mathrm{UFC} / \mathrm{mL}$ estimado nos dias um e sete para 90UFC/mL no dia 14 e $190 \mathrm{UFC} / \mathrm{mL}$ no dia 21.

Tabela 5. Médias da contagem de bolores e leveduras em ovos integrais comerciais e galados pasteurizados e armazenados sob temperatura de refrigeração até 21 dias

\begin{tabular}{|c|c|c|c|c|}
\hline \multirow{2}{*}{ Tipo de ovo } & \multicolumn{4}{|c|}{ Contagem de bolores por UFC/mL por dia de armazenamento } \\
\hline & 1 & 7 & 14 & 21 \\
\hline Comerciais & $<1,0 \times 10^{1} \mathrm{est}^{\mathrm{Aa}}$ & $<1,0 \times 10^{1}$ est $^{\mathrm{Aa}}$ & $<1,0 \times 10^{1} \mathrm{est}^{\mathrm{Aa}}$ & $3,5 \times 10^{1 \mathrm{Aa}}$ \\
\hline Galados & $<1,0 \times 10^{1} \mathrm{est}^{\mathrm{Ba}}$ & $<1,0 \times 10^{1} \mathrm{est}^{\mathrm{Ba}}$ & $9,0 \times 10^{1}$ Aa & $1,9 \times 10^{2}$ Aa \\
\hline
\end{tabular}

Médias seguidas de letras distintas, maiúsculas na linha e minúsculas na coluna, diferem entre si pelo teste de Kruskal - Wallis $(\mathrm{P}<0,05)$ para a comparação das médias dos ovos, e pelo teste de Friedman para a comparação das médias em cada tipo de ovos $(\mathrm{P}<0,05)$. 
Dias et al. (2002), ao avaliarem 33 amostras de ovo integral pasteurizado, encontraram $100 \%$ das amostras com valores abaixo de 100UFC/g. Esse aumento de bolores e leveduras ocorrido nos últimos dias indica a possível contaminação após o processamento, advinda do meio ambiente ou de resultado de manipulação em condições higiênico-sanitárias insatisfatórias, visto que a exposição do produto a temperaturas elevadas inviabiliza a sobrevivência desses microorganismos em alimentos. $\mathrm{O}$ controle de qualidade com o uso da contagem de bolores e leveduras no ovo pasteurizado é um bom indicador de problemas na higiene, na estocagem ou no transporte. De acordo com os resultados, o prazo de validade encontrado para o ovo integral comercial pasteurizado foi de 14 dias, e para o ovo integral galado pasteurizado de sete dias, pois, após estes períodos, os ovoprodutos não se encontraram aptos ao consumo.

\section{CONCLUSÕES}

O tipo de matéria-prima, ovo comercial e ovo galado, empregado para a produção de ovo integral pasteurizado refrigerado, influencia na sua qualidade, e o ovo integral galado pasteurizado apresenta qualidade mais baixa em relação à qualidade do ovo integral comercial pasteurizado, sendo que o período de validade desses produtos pode ser de sete e 14 dias, respectivamente.

\section{AGRADECIMENTOS}

Os autores agradecem o auxílio do Colegiado de Pós-graduação em Ciência Animal, por fornecer fundos para publicação desta pesquisa e do Conselho Nacional de Desenvolvimento Científico e Tecnológico $(\mathrm{CNPq})$, por fornecer bolsa de estudo. Os autores agradecem também ao Laboratório de Segurança Microbiológica em Alimentos (LSMA) do Instituto Mineiro de Agropecuária (IMA), por viabilizar as análises realizadas neste projeto.

\section{REFERÊNCIAS}

ASSOCIATION of Official Analytical Chemists. 2001. Disponível em URL: 〈http://www.aoac.gov.br〉 Acessado em: 2 jun. 2009.

AMERICAN egg board 2004. Disponível em: www.aeb.br, Acessado em: 20 nov. 2009.

ARAGON-ALEGRO L.C.; SOUZA, K.L.O.; SOBRINHO, P.S.C. et al. Avaliação da qualidade microbiológica de ovo integral pasteurizado produzido com e sem a etapa de lavagem no processamento. Cienc. Tecnol. Aliment., v.25, p.618622,2005

BALL, H.R.; HAMID-SAMIMI, M.; FOEGEDING, P.M.; SWARTZEL, K.R. Functionality and Microbial Stability of Ultrapasteurized, Aseptically Packaged Refrigerated Whole Egg. J. Food Sci., v.52, p.12121218,1987

BRASIL, Ministério da Agricultura Pecuária e Abastecimento. Portaria $\mathrm{n}^{\circ} 01$ de 21 de fevereiro de 1990. Normas Gerais de Inspeção de Ovos $e$ Derivados. Brasília, 1990. Disponível em: <www.agricultura.gov.br> Acessado em: 21 ago. 2009.

BRASIL, Ministério da Agricultura Pecuária e Abastecimento. RESOLUÇÃO $\mathrm{N}^{\circ} 005 \quad \mathrm{DE}$ 05 DE JULHO DE 1991. - Padrão de Identidade e Qualidade para o Ovo Integral. Disponível em: <www.agricultura.gov.br> Acessado em: 21 ago. 2009.

BRASIL. Ministério da Agricultura, Pecuária e Abastecimento. Regulamento de Inspeção Industrial e Sanitária de Produtos de Origem Animal. Decreto $n^{\circ}$ 30.691, de 29 de março de 1952, e alterações. DOU. Brasília atualizado em 1997. Disponível em: <www.agricultura.gov.br> Acessado em: 23 ago. 2009.

BRASIL. Ministério da Agricultura. Secretaria Nacional de Defesa Agropecuária. Laboratório Nacional de Referência Animal. Métodos analíticos oficiais para controle de produtos de origem animal e seus ingredientes: métodos físicos e químicos. Brasília, DF, v.2, 1999. Disponível em: <www.agricultura.gov.br> Acessado em: 23 ago. 2009.

BRASIL, Ministério da Agricultura Pecuária e Abastecimento. Instrução Normativa 62, de 26 de agosto de 2003. Métodos analíticos oficiais para análises microbiológicas para o controle de produtos de origem animal e água. Disponível em: <www.agricultura.gov.br> Acessado em: 21 ago. 2009. 
DIAS, A.P.; AJZENTAL, A.; CALIL, R.M. Avaliação da microbiota pré e pós-pasteurização do ovo integral líquido. Hig. alim., v.16, p.127-133, 2002.

FRANCO, B.D.G.M.; LANDGRAF, M Microbiologia de alimentos. São Paulo: Atheneu, 1996. 182p.

HAMID-SAMIMI, M.H.; SWARTZEL, K.R. Pasteurization design criteria for production of extended shelf-life refrigerated liquid whole egg. $J$. Food Process. Preserv., v.8, p.219-234, 1985.

HARA-KUDO, Y.; TAKATORI, K. Microbial quality of liquid egg and Salmonella infection status in japan. J. Food Hyg. Soc. Japan, v.50, p.35-40, 2009.
JAY, J.M.; LOESSNER, M.J.; GOLDEN, D.A. Modern food microbiology. 7.ed. New York: Springer, 2005, cap. 23, p.545-566.

KOBLITZ, M.G. Bioquímica de Alimentos. Rio de Janeiro: Guanabara Koogan, 2008. v.1, p.126-152.

STATISTICAL analysis system - SAS - INSTITUTE INC. SAS/STAT User's guide. Version 8, Cary, NC: SAS Institute Inc., 1999.

SAMPAIO, I.B.M. Estatística aplicada à experimentação animal. 2.ed. Belo Horizonte: FEPMVZ, 2002. 265p.

STADELMAN, W.J.; COTTERILL, O.J. Egg science and Technology. 4.ed. New York: Food Products, 1995. 591p. 